\title{
Numerical Simulation on Heat Pipe Heat Exchanger: Effects of Different Ambient Temperature
}

\author{
Bing Xia, Jinghong Lian, Yebin Yin, Guang Yang, Yue Yang, Xiang Gou ${ }^{a}$, \\ Enyu Wang, Liansheng Liu, Jinxiang Wu
}

School of Energy and Environmental Engineering, Hebei University of Technology, Tianjin 300401, China

${ }^{a}$ Corresponding author email: gouxiang@sina.com

Keywords: Heat pipe; Heat exchanger; Numerical simulation; Temperature field

\begin{abstract}
Heat pipe heat exchanger is one of the widely used equipment in the industrial field with effective heat transfer. Based on the advantages of the numerical simulation software FLUENT, the design and numerical simulation are carried out. Six cases of different ambient temperature have been studied in this paper include summer and winter. Heat recovery rates are not the same in different seasons. For the larger temperature difference between inside and outside, the rate of heat recovery can reach $56.14 \%$ in winter.
\end{abstract}

\section{Introduction}

Energy shortage is a serious problem in the world. Saving energy and protecting the environment is the two major problems facing the national economy [1,2].Heat pipe is a new type of high efficiency heat transfer element. In recent years, due to the shortage of energy and the rapidly development of heat pipe technology, the application of heat pipe heat exchanger in heat recovery of heat energy has achieved good results[3].In order to create a comfortable shopping and working environment, the air-conditioned buildings need for a large amount of ventilation[4-6].The heat pipe ventilation heat exchanger is a kind of ventilation equipment, which integrates heat recovery and air purification[7-9].Based on the advantages of the numerical simulation software FLUENT, the design and numerical simulation are carried out. In this work, different cases of ambient temperature outside include summer and winter had been studied [10-11].

\section{Model design and establishment}

Heat pipe heat exchanger designs purposes for preheating the fresh air and save energy. According to the working principle of the heat pipe, it should be divided into evaporation section and condensation section, which is separated into the hot air chamber and the cold air exchange chamber[12-13].The following parameters should be determined prior to design: volumetric flow rate of hot air in standard condition $\left(\mathrm{V}_{\mathrm{f}}^{\mathrm{h}}\right)$,volumetric flow rate of cold air in standard condition $\left(\mathrm{V}_{\mathrm{f}}^{\mathrm{c}}\right)$, hot air temperature $\left(\mathrm{t}_{\mathrm{hf}}\right)$,lowest temperature of hot air $\left(\mathrm{t}_{\mathrm{h} 2}\right)$,inlet temperature of cold $\operatorname{air}\left(t_{c 1}\right)$,heat pipe arrangement, geometry parameter of heat pipe, fins parameter, heat released by hot $\operatorname{air}\left(\mathrm{Q}_{\mathrm{h}}\right)$, heat absorption by cold air $\left(\mathrm{Q}_{\mathrm{c}}\right)$, outlet temperature of cold air $\left(\mathrm{t}_{\mathrm{c} 2}\right)$, logarithmic mean temperature difference $\left(\triangle t_{m}\right)$,etc. The following formulas are used to calculation:

$$
\begin{aligned}
& \mathrm{Q}_{\mathrm{h}}=\mathrm{V}_{\mathrm{f}}^{\mathrm{h}} \cdot \rho_{\mathrm{f}}^{\mathrm{h}} \cdot \mathrm{C}_{\mathrm{ph}}\left(\mathrm{t}_{\mathrm{h} 1}-\mathrm{t}_{\mathrm{h} 2}\right) \\
& \mathrm{Q}_{\mathrm{c}}=(1-\eta) \mathrm{Q}_{\mathrm{h}} \\
& \mathrm{t}_{\mathrm{c} 2}=\mathrm{t}_{\mathrm{c} 1}+\frac{\mathrm{Q}_{\mathrm{c}}}{\mathrm{V}_{\mathrm{f}}^{\mathrm{c}}+\mathrm{C}_{\mathrm{pc}} \cdot \rho_{\mathrm{f}}^{\mathrm{c}}} \\
& \Delta \mathrm{t}_{\mathrm{m}}=\frac{\left(\mathrm{t}_{\mathrm{h} 1}-\mathrm{t}_{\mathrm{c} 2}\right)-\left(\mathrm{t}_{\mathrm{h} 2}-\mathrm{t}_{\mathrm{c} 1}\right)}{\ln _{\mathrm{h} \mathrm{t}-\mathrm{t}_{\mathrm{c} 2}}^{\mathrm{t}_{\mathrm{h} 2}-\mathrm{t}_{\mathrm{c} 1}}}
\end{aligned}
$$


CFD software for calculating the three-dimensional turbulent flow is used in this paper. The whole model has two channels of cold air and hot air flow respectively. Indoor parts include cold air inlet and hot air outlet, and cold air outlet and hot air inlet to the outdoor part. Model design size is $550 \mathrm{~mm} \times 300 \mathrm{~mm} \times 100 \mathrm{~mm}$, which includes $12 \varphi 8$ heat pipe. Heat pipes through the hot and cold air flow between the two channels and maintain a triangular arrangement of cross row. The fins of adjacent rows staggered to keep uniform distribution.

Heat pipes and fins are arranged into the fluid-solid coupling wall surface and the heat pipe is arranged for solid region especially. In order to ensure the accuracy of the calculation of the internal heat pipe and fins are carried out the grid encryption and the final grids are divided into 620 thousands. The simulation is based on unsteady, implicit solution based on pressure. Turbulence model is modeled by the standard k-epsilon method. Cold and hot air inlet are both provided with boundary conditions for velocity inlet boundary conditions at the velocity of $0.04 \mathrm{~m} / \mathrm{s}$. Six cases have been studied in this paper as depicted in Table 1.

Table 1.Cases of different ambient temperature

\begin{tabular}{cccccccc}
\hline Season & \multicolumn{3}{c}{ Summer } & \multicolumn{3}{c}{ Winter } \\
\hline Case & & 1 & 2 & 3 & 4 & 5 & 6 \\
Temperature (K) & $\begin{array}{c}\text { cold air } \\
\text { inlet } \\
\text { hot air } \\
\text { inlet }\end{array}$ & 299 & 299 & 299 & 260 & 265 & 270 \\
\hline
\end{tabular}

\section{Simulation results and analysis}

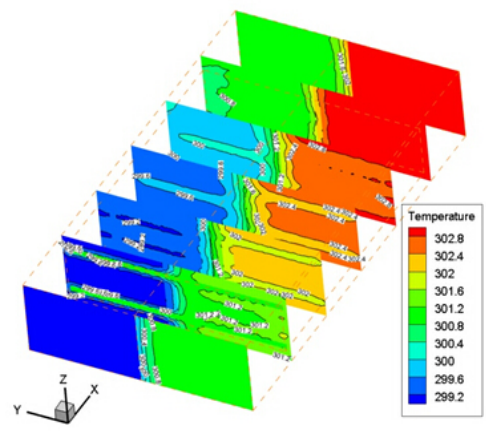

Case 1. Summer 299K-303K

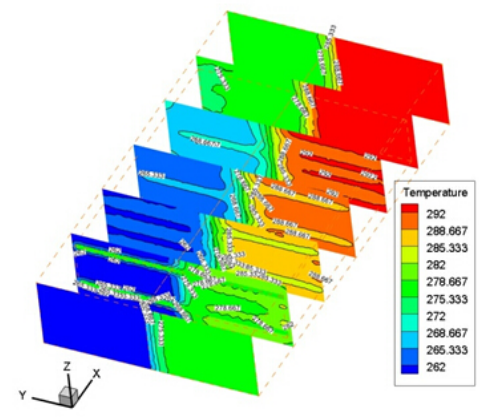

Case 4. Winter 260K-294K

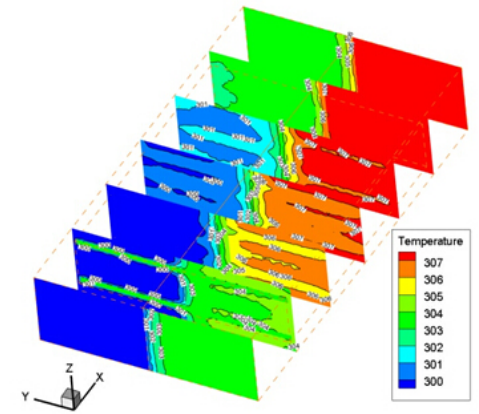

Case 2. Summer 299K-308K

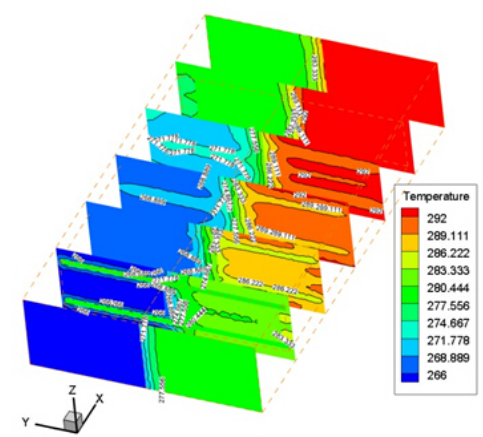

Case 5. Winter 265K-294K

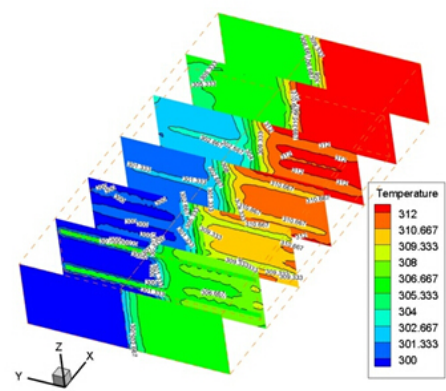

Case 3. Summer 299K-313K

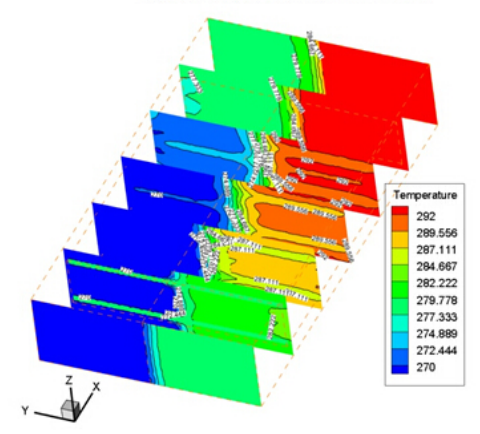

Case 6. Winter 270K-294K

Fig.1. Temperature diagram of sections perpendicular to the $\mathrm{Y}$ axis at different cases

It is the temperature distribution in the heat exchanger at different ambient temperature as shown in Fig.1.The temperature difference between air inlet and outlet is decreased, and the heat transfer effect of the baffles obviously. In the cases of summer, the temperature of hot air outlet is 
decreased with the increasing of the ambient temperature outside. It also can be described as the temperature of cold air outlet is increased with the decreasing of the ambient temperature outside in winter. For the analysis mentioned above, a conclusion can be found that the higher temperature difference between inside and outside, the higher heat transfer for this model.
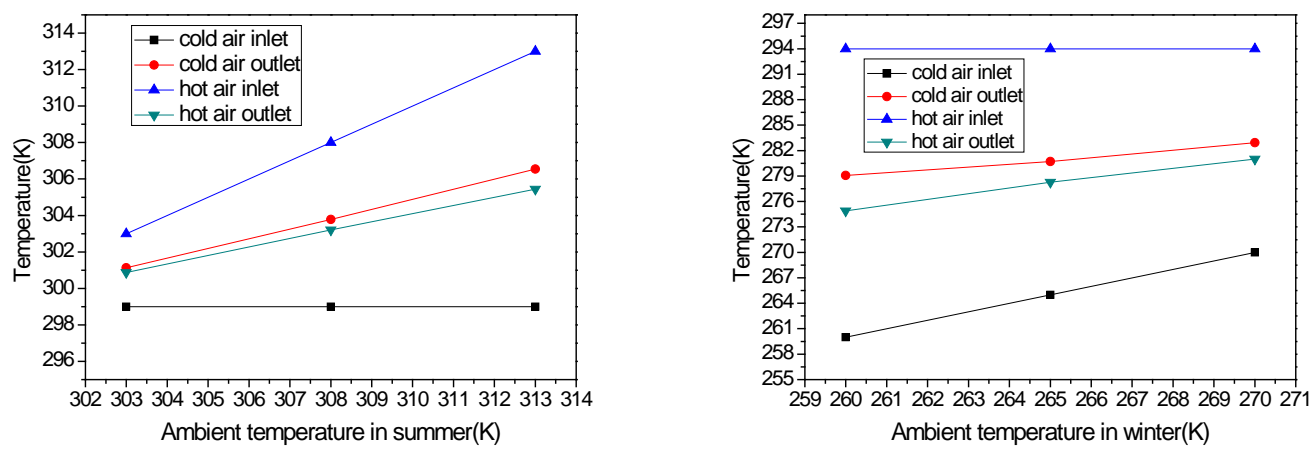

Fig.2.The average temperature of air inlet and outlet in different cases

Fig.2. shows that in the cases of summer, the temperature of cold air inlet is a constant value. With the increases of ambient temperature outside, the temperature of cold outlet and hot outlet is increasing. The temperature of hot air inlet reaches up to $305.4 \mathrm{~K}$ when the ambient temperature outside is $313 \mathrm{~K}$. It also can be described as the similar pattern in the cases of winter. By contrasting the different cases of winter, it can be found that, temperature of hot air inlet is a constant value. With the increases of ambient temperature outside, the temperature of cold outlet and hot outlet is increasing. The temperature of cold air inlet reaches up to $279.08 \mathrm{~K}$ when the ambient temperature outside is $260 \mathrm{~K}$.
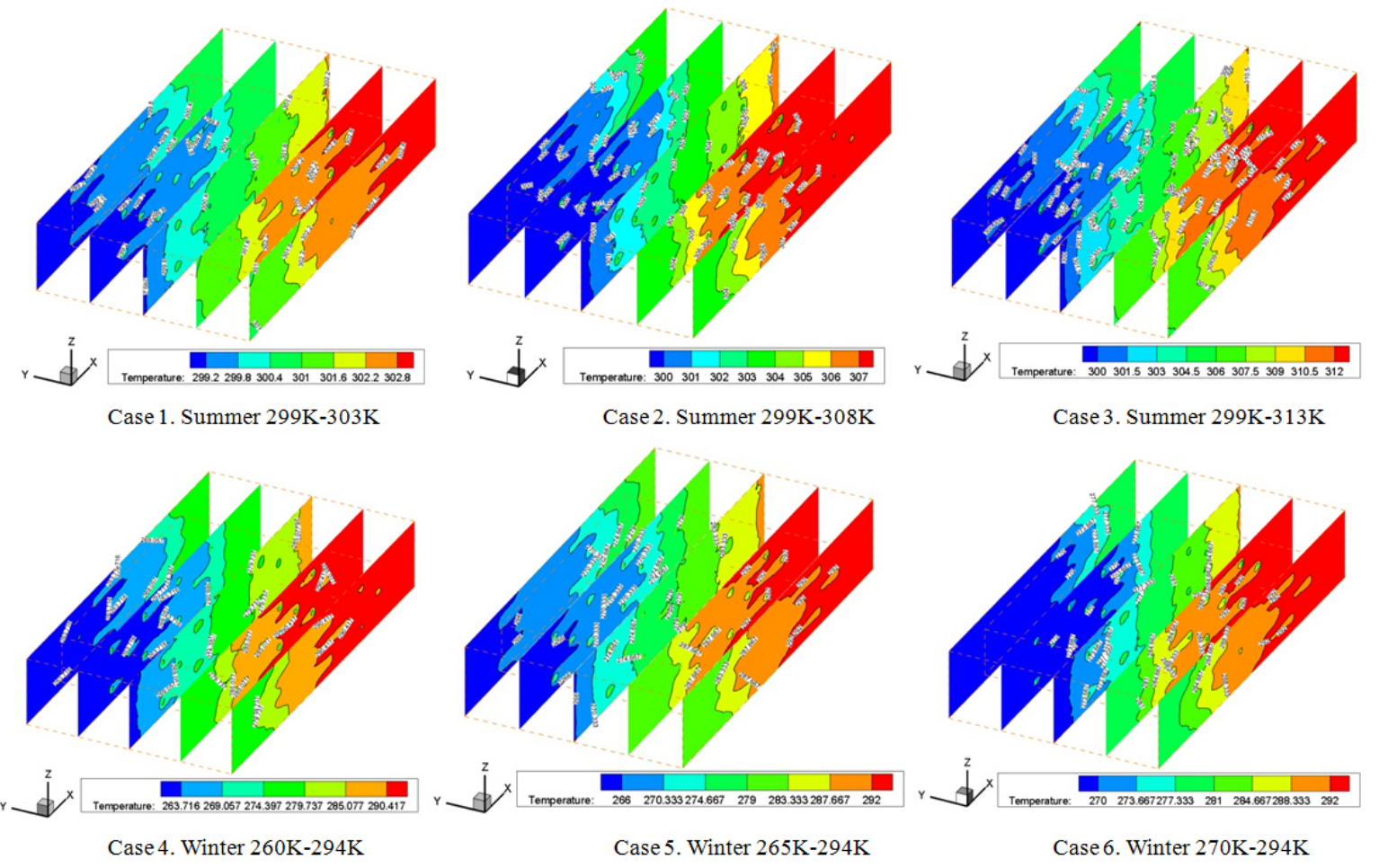

Fig.3. Temperature diagram of sections perpendicular to the $\mathrm{X}$ axis at different cases

Temperature distribution in the heat exchanger of sections perpendicular to the $\mathrm{X}$ axis at different cases are show in Fig.3. Whether it is summer conditions or winter conditions, the effects of heat transfer are more obviously with the increasing of the temperature difference of inside and outside. Through the analysis of temperatures distribution, the conclusion above can also be verified. 
For the summer case, the temperature of cold air increases only $2.21 \mathrm{~K}$ at the case of the ambient temperature of outside is 303K. And for this case, the temperature difference is the lowest in this simulation.
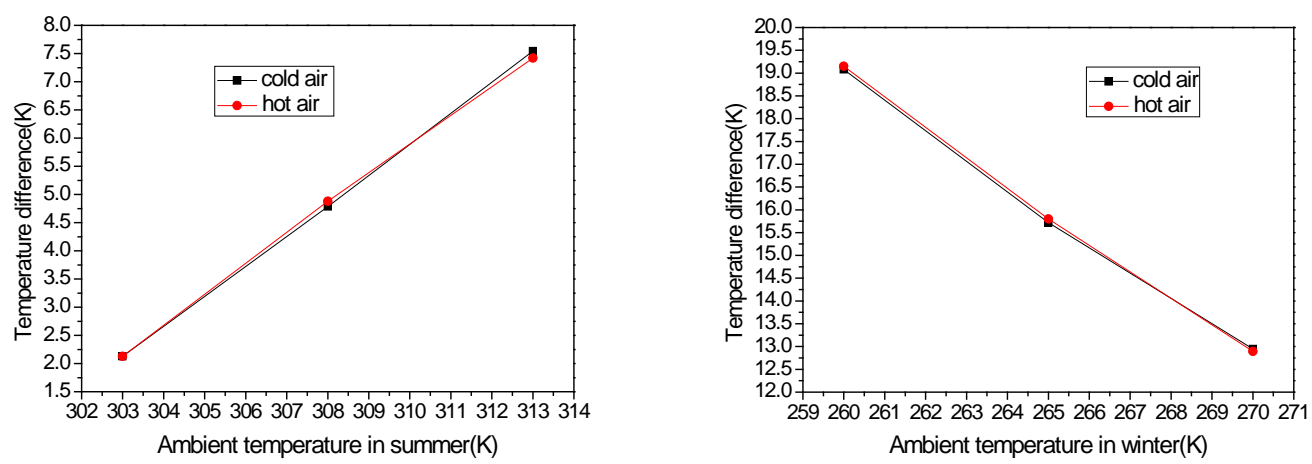

Fig.4. Temperature difference of air inlet and outlet in different cases

Temperature difference of air inlet and outlet are show in Fig.4. In winter, temperature difference between inside and outside is higher that summer. And for this case, through the heat exchanger, the temperature of cold air at the outlet reaches up $19.08 \mathrm{~K}$ at most.

By contrasting the heat recovery rates of different cases in Fig.5, it can be found that, heat recovery rate is $53.91 \%$ at the lowest temperature difference between inside and outside in case of summer. While for winter, heat recovery rate can reaches $56.14 \%$ at the largest temperature difference in the case of winter. Through the analysis above, it can be found that the rate of heat recovery in winter is higher that summer for the larger temperature difference of inside and outside.
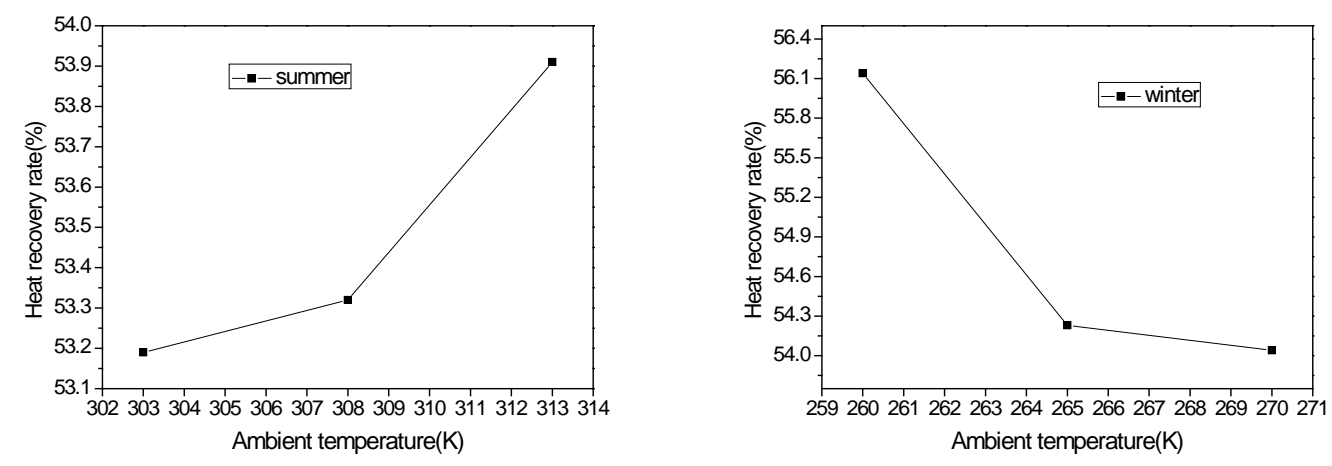

Fig.5. Heat recovery rate of different cases

\section{Conclusions}

(1)The heat pipe heat exchanger is a kind of ventilation equipment, which integrates heat recovery and air purification. Based on the advantages of the numerical simulation software FLUENT, the design and numerical simulation are carried out.

(2)In this model, the ambient temperature has great influence to the air temperature through the heat pipe heat exchanger. The temperature of hot air outside can decreases $7.54 \mathrm{~K}$ in summer case. In winter, the temperature of cold air outside can increases $19.08 \mathrm{~K}$ at most. Heat exchange effect is better in winter case in this research.

(3)Heat recovery rates are not the same in different seasons. For the larger temperature difference between inside and outside, the rate of heat recovery can reach $56.14 \%$ is higher in winter, and it can reach $56.14 \%$ at most. 


\section{Acknowledgements}

This work was financially supported by the National Natural Science Foundation of China (Grant No.51276055) and the Hebei Applied Basic Research Program of China (Grant No. 13964503D).

\section{References}

[1] S.M. Sun, H. Zhang, Analysis of CFD simulation with experiment of heat transfer and pressure drop for heat pipe heat exchanger, Journal of Nanjing University of Technology. 26(2004)62-66.

[2] Z.H. Liu, L. Jin, X.H. Wang, P.H. Li, X.M. Yang, Miniature ventilating device with heat pipe heat exchanger applied in laboratory, Heating Ventilating and Air Conditioning. 40 (2012) 10-12.

[3] P. Meisel, M. Jobst, W. Lippmann, A. Hurtado, Design and manufacture of ceramic heat pipes for high temperature applications, Appl. Therm. Eng. 75 (2015) 692-699.

[4] H. Mroue, J.B. Ramos, L.C. Wrobel, H. Jouhara, Experimental and numerical investigation of an air-to-water heat pipe-based heat exchanger, Appl. Therm. Eng. 78 (2015) 339-350.

[5] Z. Zhang, Y.M. Ding, C.F. Guan, H. Yan, W.M. Yang, Heat transfer enhancement in double-pipe heat exchanger by means of rotor-assembled strands, Chem. Eng. Process. 60(2012)26-33.

[6] H. Jouhara, R. Meskimmon, Experimental investigation of wraparound loop heat pipe heat exchanger used in energy efficient air handling unit, Energy. 35(2010)4592-4599.

[7] Y.H. Yau, M. Ahmadzadehtalatapeh, A review on the application of horizontal heat pipe heat exchangers in air conditioning systems in the tropics, Appl. Them. Eng. 30(2010)77-84.

[8] I.A. Badruddin, N.J.S. Ahmed, Numerical investigation of the performance of a triple concentric pipe heat exchanger, Int. J. Heat Mass Transfer. 75(2014)165-172.

[9] M. Cavazzuti, E. Agnani, M.A. Corticelli, Optimization of a finned concentric pipe heat exchanger for industrial recuperative burners, Appl. Them. Eng. 84 (2015)110-117.

[10] E.G. Jung, J.H. Boo, Thermal analytical model of latent thermal storage with heat pipe heat exchanger for concentrated solar power, Solar Energy. 102(2014)318-332.

[11] Y. Yuan, Y.J. Lu, H.S. Bao, Y.D. Wang, W. Wang, A.P. Roskilly, Investigation of a heat pipe heat exchanger integrated with a water spray for the heat recovery from boil exhaust gas, Energy Procedia.61(2014)2141-2144.

[12] D.D. Zhu, D. Yan, Z. Li, Modeling and applications of annual energy-using simulation module of separated heat pipe heat exchanger, Energy and Buildings. 57 (2013) 26-33.

[13] S.N. Kazi, G.G. Duffy, X.D. Chen, Validation of heat transfer date for fiber suspensions in coaxial pipe heat exchangers, Exp. Therm Fluid Sci.38(2012)210-222. 